\title{
Consumer-Oriented Product Development: The Conceptualization of Novel Food Products Based on Spirulina (Arthrospira platensis) and Resulting Consumer Expectations
}

\author{
Stephanie Grahl, ${ }^{1}$ Micha Strack, ${ }^{2}$ Ramona Weinrich, ${ }^{3}$ and Daniel Mörlein ${ }^{1}{ }^{1}$ \\ ${ }^{1}$ Department of Animal Sciences, Chair Quality of Animal Products, University of Göttingen, Albrecht-Thaer-Weg 3, \\ 37075 Göttingen, Germany \\ ${ }^{2}$ Georg-Elias-Müller-Institute of Psychology, University of Göttingen, Goßlerstraße 14, 37073 Göttingen, Germany \\ ${ }^{3}$ Centre for Biodiversity and Sustainable Land Use and Department of Agricultural Economics and Rural Development, \\ Chair Management in Agribusiness, University of Göttingen, Platz der Göttinger Sieben 5, 37073 Göttingen, Germany \\ Correspondence should be addressed to Daniel Mörlein; daniel.moerlein@uni-goettingen.de
}

Received 4 May 2018; Accepted 5 July 2018; Published 31 July 2018

Academic Editor: Marina Carcea

Copyright (c) 2018 Stephanie Grahl et al. This is an open access article distributed under the Creative Commons Attribution License, which permits unrestricted use, distribution, and reproduction in any medium, provided the original work is properly cited.

\begin{abstract}
The world population is steadily growing and the demand for protein increases along with it, yet our planetary resources are finite. Spirulina (Arthrospira platensis) is an underutilized protein source suitable for human nutrition, and little is known about the use of spirulina as a food and the associated consumer opinion. New product development (NPD) requires early and active participation of consumers for the success of new products; therefore, a mixed method approach was applied to conceptualize (sensory profiling of spirulina extrudates and expert interviews) and then evaluate consumer's willingness to try (consumer survey) three innovative products: pasta filled with spirulina, maki-sushi filled with spirulina, and spirulina jerky. To evaluate the consumer orientation towards novel, spirulina-based products, 1035 consumers from three countries (GER, $n=348$; FR, $n=337$; NL, $n=350$ ) were surveyed regarding their hedonic opinion about these concepts. A photo of each product was systematically accompanied by a benefit description covering health, sustainability, or innovation. Each consumer sequentially evaluated three combinations thereof (Latin square design). A multilevel model was used to analyze consumers' responses regarding novelty, interest, overall liking, and expected flavor liking. Overall, spirulina-filled pasta was identified as the most preferred product. Mediation analysis revealed that this could be partly explained by familiarity with products in that category (i.e., pasta more than sushi and jerky). In conclusion, all spirulina product concepts would work equally well, if pasta, sushi, and jerky were similarly familiar to the target consumer population. All tested benefits were equally accepted with each product, with the exception that spirulina jerky would have to be marketed as being innovative. Country differences can be neglected.
\end{abstract}

\section{Introduction}

The future protein supply is of major concern, as according to predictions, the world population will reach 8.9 billion in 2050 and peak at 9.2 billion by 2075 [1]. Simultaneously, the worldwide middle class is expanding accompanied by increased living standards which results in a high demand for animal-based protein [2]. The production of conventional protein, particularly the conversion from plant into animal protein, puts a lot of pressure on land and freshwater resources [3]. Therefore, new approaches to tackle the future protein supply need to be implemented.

The microalga spirulina (Arthrospira platensis), with its protein content of $63 \%$ dry matter [4], is a promising food ingredient when it comes to enlarging the repertoire of protein sources available for human consumption. While spirulina already plays a role in human nutrition in Africa $[5,6]$ and is widely used in parts of Asia due to its health benefits [7], European consumers are not yet familiar with the microalga on a broad scale. Even though spirulina was 
identified as a "source of nonconventional protein of considerable interest" [8] 35 years ago, product prototypes based on new protein sources, like spirulina, rarely exist [2]. One reason may be the limited knowledge regarding application in recipes and the rarity of convenience products in supermarkets. Most often in western countries, spirulina is used as a food supplement, additive, or dye and is marketed as powder, pills, or capsules [7], while actual foods are less widespread. To promote a broader use of spirulina, the shift from supplement to food ingredient needs to be pushed forward and innovative novel products need to be developed.

Studies show that novel food products are most successful when they are developed on the basis of consumer orientation $[9,10]$. In order to create potentially successful consumer-oriented products, novel product concepts incorporating spirulina extrudates were developed based on sensory data since extrusion was shown to be suitable to texturize protein utilizing spirulina [11]. Expert interviews were conducted and followed by an online study designed to confront consumers with these concepts and incite their reaction towards these new products. In addition, consumers do not value products intrinsically, but much of the value is derived from the benefits a product delivers through certain product characteristics [12]. Even more so, successful novel food products are hinged on the degree to which they provide consumer-sought benefits [13]. Novel products that carry concrete and relevant benefits, but are not substantially changed from already available products, are likely to be well accepted by consumers [14]. Spirulina inherits various beneficial traits that were of interest in this study, namely, health, sustainability, and innovation.

Spirulina's health benefits relate to plant-derived proteins and polyunsaturated fatty acids, while the protein source is cholesterol-free and also low in calories. Minerals and antioxidants complete the "healthy" nature of spirulina $[15,16]$. The substantial content of $\gamma$-linolenic acid $(18: 3$ $\omega-6)$ deserves attention because spirulina is one of the best known sources [17]. Polyunsaturated fatty acids (PUFAs), of which $\gamma$-linolenic acid is one, have been shown to have antiinflammatory effects $[18,19]$. Spirulina protein contains all essential amino acids [20] and therefore can contribute to a health-oriented diet.

The sustainability benefits are associated with a localized production potential using marginal amounts of land for production in tanks on land (as demonstrated by various companies in Western Europe which are producing spirulina (e.g., Roquette-Klötze in Klötze (Saxony-Anhalt), Germany)), allowing for increased independence from soy imports that require high land occupation [21] and cause greenhouse gas emissions through long transportation routes [22]. To date, the technology is still in its infancy stages and the sustainability remains dependent on production conditions [23], but improvements to production technology can be implemented to make microalgae more sustainable in the future (e.g., usage of renewable energy to operate photo bioreactors) [24].

Spirulina as a mostly unknown ingredient in European food products brings about its innovative characteristics.
Therefore, products containing spirulina as a main ingredient (not just a supplement) could be framed as a trendy snack with a special taste, an edible innovation, or a culinary highlight. Various publications deal with the incorporation of spirulina in food applications, for example, bread $[5,25]$, cereals and biscuits [26-28], pasta [29, 30], or probiotic milk drinks [31]. However, such food products are seldom commercially marketed, partly because spirulina was shown to have a negative effect on sensory characteristics $[5,31]$.

Finally, although the protein gap problem is Europewide; there remain culturally and regionally dependent food product perceptions and consumption attitudes and behaviors [14, 32]. A standardized novel food product could be marketed throughout the continent or different products may appeal to different countries. Therefore, a cross-national approach was applied herein to allow for a countrycomparison of whether the spirulina products fulfill similar expectations across different consumer bases or not. Studies confirm cross-cultural differences regarding vegetarianism [33], protein diets [34], sensory appeal, and convenience of food [35], which are pertinent points regarding consumer expectations to spirulina-based novel food products. This study investigates consumer expectations when products are presented with corresponding beneficial traits to anticipate which products (if any) should be pursued for prototype development and sensory testing. However, testing all three products directly in a consumer test including degustation in a sensory lab (be it in the context of a meal or without) would have been costly and time-consuming regarding product development and testing time. Therefore, to reduce resource expenditure to a necessary level, this current concept study provided initial insight into the most promising product category for integrating the microalga spirulina into European dietary habits.

Altogether, the study answers four research questions:

(i) Which of the actual products is the most popular according to consumers, when spirulina is included as a main ingredient?

(ii) Does familiarity with the product category explain overall liking of the new spirulina products?

(iii) Which of the benefits, when presented in connection with a product, has the highest impact on overall liking?

(iv) Are the answers to the questions I-III countrydependent?

\section{Materials and Methods}

2.1. Expert Interviews and Product Conceptualization. Due to restricted product experience, consumers are generally a poor source of inspiration and creativity [36], and fixation on existing products may hinder "thinking out of the box" [37]. Thus, prior to factoring in consumer input, it was decided to conduct in-depth interviews with culinary experts active in their field to initiate product conceptualization. Four expert interviews were conducted in 2017, where an already developed spirulina extrudate [11] (the basis for the 
products used in this study) was presented to sample as an instigator. During the interviews, a chef, an aroma researcher, an algae retailer, and a celebrity food-expert were introduced to various product ideas like pasta, sushi, salad, nuggets, crispy bites, polenta with spirulina, stuffed puff pastry, and jerky to hear about their opinion regarding potential development in these directions.

Based on the interviews, the three most convincing and promising product ideas were determined to be spirulinafilled pasta, spirulina-filled maki-sushi, and spirulina jerky as a vegan alternative to beef jerky (Figure 1). As McGee [38] states, the key to pasta's appeal are its moist, yet substantial texture and its neutral flavor. Particularly, the latter renders pasta dough into a suitable partner for a broad range of ingredients, and the interviewed experts came to the same conclusion. Maki-sushi was described as a promising concept because consumers know conventional sushi contains nori algae, which is dark green to black, similar to spirulina. It was assumed that consumers' knowledge and expectations of conventional sushi made with nori could be transferred to the microalga spirulina with its dark coloring and could provoke an expected color-flavor fit. Finally, the idea to produce a vegan version of a dried meat snacks stems from the initial use of extrudates based on high moisture extrusion cooking, namely, meat analogues. It was assumed that extrudates could lend the spirulina jerky the chewiness and bite-texture expected while enjoying regular beef jerky. In addition, beef jerky has usually a dark color due to the drying process of the meat. The experts' opinion was that a vegan dried snack makes sense for consumers as it extends the offer of dried "on-the-go" snacks to a product that is convenient, savory, and rich in protein. Therefore, the 3 chosen products cover a broad range of novelty (i.e., well-known pasta to trending jerky) but are not completely unknown, therefore making them optimal to confront consumers with. After the products were identified, various prototypes were produced manually. The products of choice were finally photographed in a professional photo studio.

2.2. Consumer Questionnaire. The aim of the questionnaire was to determine which product was most accepted and which benefits affected the acceptability. In order to ensure that participants had adequate background information, prior to evaluating product concepts, the participants were primed with general information about spirulina as follows:

"The microalga spirulina is characterized by its high protein content and is therefore suitable to be eaten as an alternative to other protein-containing foods such as meat or dairy products. That is why we are researching to expand the food supply with spirulina. Our mission is supported by the benefits of spirulina in terms of the environment and a healthy diet. In addition, spirulina products are a novelty to the food market, helping us to make the future of food production more sustainable and to set new trends."

Next to the text, a picture of a small pile of spirulina powder was shown. Participants were asked to rate how relevant they found the information from "not relevant at all" (1) to "very relevant" (9).
Then, the consumers were exposed to three spirulinabased products (filled pasta (a), sushi (b), and jerky (c); Figure 1) and three benefit orientations (environmentally sustainable, healthy, or innovative). The products were shown on photos and accompanied by a brief text explaining a benefit orientation. A Latin square combinatorics allowed each benefit and each product to be presented to a single consumer only once. The participants evaluated 3 productbenefit combinations consecutively, where the product was visually shown in a photo and the benefit was contextualized adjacently (Table 1). Using 9-point hedonic rating scales, participants answered questions regarding novelty ("not at all novel" (1) to "very novel" (9)), interest ("not at all interesting" (1) to "very interesting" (9)), overall liking ("dislike extremely" (1) to "like extremely" (9)), and expected flavor liking ("very bad" (1) to "very good" (9)).

Finally, participants were asked whether they had known of the microalga prior to the survey, and whether they had already tasted it. Participants were also asked how often they eat conventional filled pasta, sushi, and beef jerky (6-point scale: $1=$ several times a week, $2=$ once per week, $3=$ every second week, $4=$ once a month, $5=$ less often than once per month, and $6=$ never). Familiarity with the product categories was derived from this question of frequency of consumption. The answers were clustered into three categories and effect coded: $+1=$ several times a month, $0=$ on a monthly basis or less often, and $-1=$ never. At the end, demographic data (city size and education) were collected.

The questionnaire was written in German and translated into French and Dutch. It was than retranslated from two independent native speakers back to German and checked for consistency. The study protocol was approved by the Ethics Committee of Georg-August-University, Goettingen.

2.3. Recruitment of Consumer Participants. An online survey was distributed through a commercial, established survey company (Research Now SSI, Frankfurt, Germany) in September 2017. A sample of 1227 surveys in total was collected across three countries. Samples, respectively representative of the German, French, and Dutch populations, were recruited via e-mail from the online panelist pool using set quotas regarding age and gender. Potential participants were screened out if they did not eat meat. After a data quality check (Section 2.4), 1035 valid interviews remained: Germany $(n=348)$, France $(n=337)$, and the Netherlands $(n=350)$. Characteristics of the final sample are shown in Table 2.

2.4. Data Quality and Analysis. In the first step, data quality was checked and mischievous respondents were removed. The questionnaire included scales on usage and attitudes which are beyond the scope of this paper but were used to clean the data by eliminating participants who were crisscrossing (11\%) or failing to answer a trap question correctly (10\%). The final sample included 1035 respondents. An ANOVA (post hoc test to differentiate between countries: Duncan) was used to compare the perceived relevance across consumers of the three countries. 


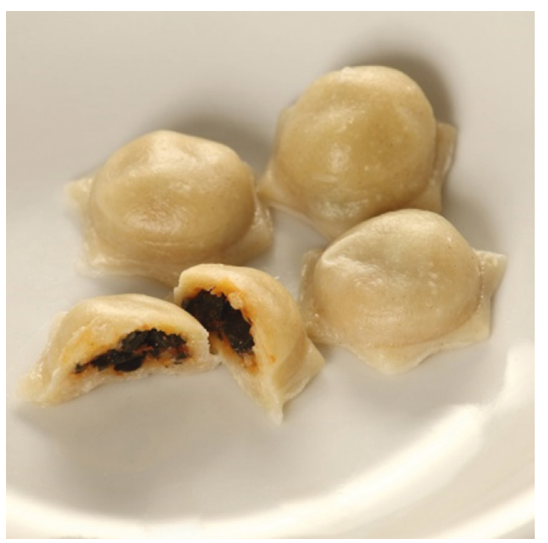

(a)

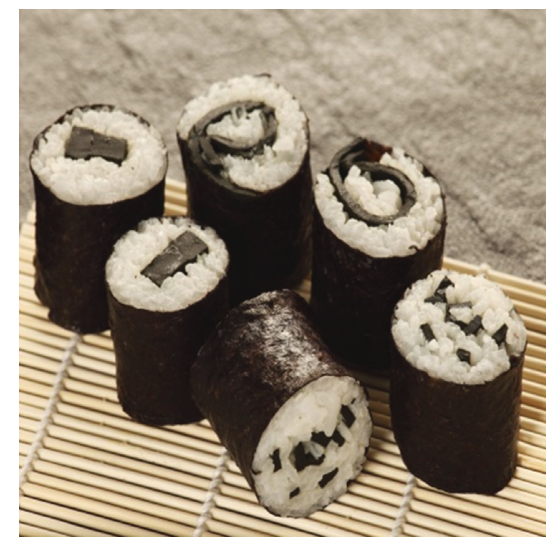

(b)

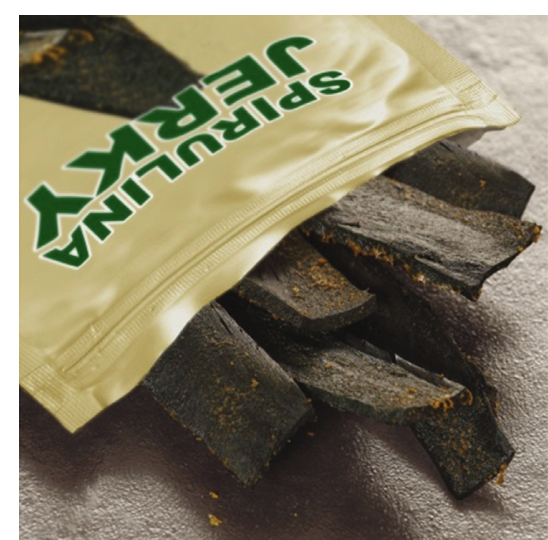

(c)

Figure 1: Pictures of spirulina-filled pasta (a), spirulina-filled sushi (b), and spirulina jerky (c) as they were shown to the consumers. The verbal benefits can be found in Table 1 .

TABLE 1

\begin{tabular}{c}
\hline Pasta \\
\hline Spirulina pasta: a healthy alternative \\
to ravioli with meat filling \\
A healthy pasta thanks to spirulina: \\
plenty of protein and polyunsaturated \\
fatty acids, cholesterol-free and low in \\
calories. Because of the minerals and \\
antioxidants, spirulina pasta is good for \\
you.
\end{tabular}
Sushi

Spirulina sushi: a healthy alternative to sushi with fish filling

Spirulina sushi is healthy and contains a lot of protein, polyunsaturated fatty acids, minerals, and antioxidants.

Unlike some fish frequently used for sushi, spirulina does not contain any mercury, which is harmful to your

health. Spirulina sushi is good for you.

Spirulina pasta: a sustainable alternative to ravioli with meat filling Spirulina is a more sustainable protein source than meat, whose production consumes a lot of land and causes

Sustainability climate-damaging $\mathrm{CO}_{2}$. The microalgae can be cultivated on a small area of land in tanks or in ponds and therefore is locally produced, just like the durum wheat in the dough. Spirulina pasta is a delicious meal with a clear conscience.

Spirulina pasta: new alternative to ravioli with meat filling

Conventional ravioli are a thing of the past! Spirulina is the basis for the pasta with a unique filling. Algae are trendy and bring their own flavor. The recipe was developed with a celebrity chef: it is star-suspicious. Spirulina pasta is an edible innovation and a culinary highlight at the same time.
Spirulina sushi: a sustainable alternative to sushi with fish filling

Spirulina is a more sustainable source of
protein than fish, as fish farms pollute the environment and overfishing leads to social conflicts. The microalgae can be cultivated regionally on a small area of land in tanks or in ponds, which saves on transport and gives the sushi a regional flair. Spirulina sushi is a highquality treat with a clear conscience.

Spirulina sushi: a new alternative to sushi with fish filling

Spirulina sushi is the food of the future:

everything from the sea, but without the animal-ethical problems of fish farming. Yet, it is rich in protein, trendy, has a characteristic taste and satisfies your hunger. All in black and white and without compromise:

Spirulina sushi is an edible innovation and a culinary highlight at the same time.
Spirulina jerky: a healthy alternative to beef jerky

Jerky made from dried beef is a typical snack, but spirulina jerky is also healthy. In addition to its high protein content to satisfy your hunger, spirulina contains polyunsaturated fatty acids, the snack is cholesterol-free, low in calories, and rich in minerals and antioxidants. Spirulina jerky is good for you.

Spirulina jerky: a sustainable alternative to beef jerky

Spirulina is more sustainable than dried Jerky beef, whose production consumes a lot of land and causes climate-

damaging $\mathrm{CO}_{2}$. The microalgae can be regionally cultivated on a small area of land in tanks or in ponds, which saves on mileage and gives the snack a regional flare. With recycled packaging, Spirulina jerky becomes a high-quality treat with a clear conscience.

Spirulina jerky: new alternative to beef jerky

Spirulina jerky, unlike jerky made from dried beef, is the food of the future: always in your pocket, durable and dry, rich in protein, and satisfying. A trendy snack with its special taste. Unlike cattle, spirulina breeding is conceivable in the city (urban farming in tanks on building facades) and perfect selfsufficiency. Spirulina jerky is an edible innovation and a culinary highlight at the same time. 
TABLe 2: Sample characteristics $(n=1035)$.

\begin{tabular}{|c|c|c|c|c|c|c|c|}
\hline \multirow{2}{*}{ Variable } & \multirow{2}{*}{ Levels } & \multicolumn{2}{|c|}{ GER $(\%)(n=348)$} & \multicolumn{2}{|c|}{ FR $(\%)(n=337)$} & \multicolumn{2}{|c|}{ NL $(\%)(n=350)$} \\
\hline & & Sample & Population & Sample & Population & Sample & Population \\
\hline \multirow{2}{*}{ Gender } & Female & 53 & 51 & 52 & 51 & 53 & 50 \\
\hline & Male & 47 & 49 & 48 & 49 & 47 & 50 \\
\hline \multirow{3}{*}{ Age } & $18-29$ & 18 & 21 & 19 & 24 & 24 & 24 \\
\hline & $30-49$ & 42 & 41 & 45 & 43 & 44 & 41 \\
\hline & $50-64$ & 40 & 38 & 36 & 33 & 32 & 34 \\
\hline \multirow{4}{*}{ Education $^{\mathrm{a}, *}$} & Low & \multicolumn{2}{|r|}{23} & \multicolumn{2}{|r|}{4} & \multicolumn{2}{|r|}{20} \\
\hline & Medium & \multicolumn{2}{|r|}{48} & \multicolumn{2}{|r|}{50} & \multicolumn{2}{|r|}{20} \\
\hline & High & \multicolumn{2}{|r|}{29} & \multicolumn{2}{|r|}{45} & \multicolumn{2}{|r|}{60} \\
\hline & Not (yet) graduated & \multicolumn{2}{|r|}{-} & \multicolumn{2}{|r|}{2} & \multicolumn{2}{|r|}{1} \\
\hline \multirow{4}{*}{ City size* } & Village (up to 5,000 inhab.) & \multicolumn{2}{|r|}{18} & \multicolumn{2}{|r|}{30} & \multicolumn{2}{|r|}{19} \\
\hline & Small town (up to 20,000 inhab.) & \multicolumn{2}{|r|}{20} & \multicolumn{2}{|r|}{19} & \multicolumn{2}{|r|}{23} \\
\hline & Medium-sized city (20,000 to 100,000 inhab.) & \multicolumn{2}{|r|}{23} & \multicolumn{2}{|r|}{29} & \multicolumn{2}{|r|}{32} \\
\hline & Big city (100,000 inhab. and more) & \multicolumn{2}{|r|}{39} & \multicolumn{2}{|r|}{22} & \multicolumn{2}{|r|}{25} \\
\hline
\end{tabular}

${ }^{*}$ No quota regarding education or city size sample; ${ }^{a}$ education levels-low: up to prevocational education; medium: secondary vocational education and preuniversity education; high: university degree; inhab. = inhabitants.

Because product-benefit combinations were nested within individual participants, multilevel modelling was applied. At level L1 the dependent variables (DV), novelty, interest, overall liking, and expected flavor liking as well as familiarity in mediation analysis were located. The fixed experimental factors product and benefit were also located at L1. The individual participant represented by a categorical ID was included as a random factor and built level L2. At L2, predictors representing individual differences (e.g., country) were included in the model. Parameters were estimated by the generalized linear mixed model (glmm) procedure in SPSS IBM 24.0 (rating DV probability distribution: normal; link function: identity), and least significant difference (LSD) was used to compare estimated marginal means. Models were compared using the Bayesian information criterion (BIC); the smaller the BIC value, the better the fit of the model. Model M0 without fixed factors revealed a large share of betweenparticipants variance, and the Intraclass correlation (ICC) showed that participants used the scale differently. The multilevel approach is specifically suited for that scenario by including the random intercept in all models. M1 introduced the experimental factors product, benefit, and their interaction, while M3 considered country moderations as well.

Model M2 tried to explain the product effect through the inclusion of familiarity with the product category on the within-participant level. It was assumed that liking would be mediated by familiarity. Mediation analysis followed the approach of Baron and Kenny [39]. To investigate mediation of the product main effect (c), models tested paths $a$ and $b$ in Figure 2 and observed whether c' declines to nonsignificance if path $\mathrm{b}$ is included.

\section{Results and Discussion}

3.1. Relevance and Foreknowledge of Spirulina. National differences in perceived relevance of spirulina were identified $(F(2,1032)=76.7 ; p=0.001)$. French consumers found spirulina to be more relevant as a food ingredient $\left(\right.$ mean $\left.=6.9^{\mathrm{a}}, \mathrm{SD}=1.6\right)$ than German $\left(\right.$ mean $\left.=5.4^{\mathrm{b}}, \mathrm{SD}=2.4\right)$ and Dutch (mean $\left.=5.0^{c}, \mathrm{SD}=2.2\right)$ consumers (means with

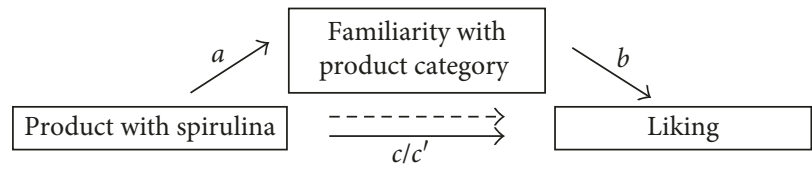

FIGURE 2: Model of a new product's acceptance mediated by the familiarity with the product category.

different superscript letters differ significantly). This might be explained by the result that $59 \%$ of the French consumers heard about microalgae before this study while $46 \%$ of the German and only 33\% of the Dutch consumers did so. Foreknowledge of microalgae generally enhanced perceived relevance of spirulina, $F(1,1033)=76.8 ; p=0.001$. However, the country effect did not disappear, when foreknowledge was included in the ANOVA, thus foreknowledge only partly mediated the country effect. Additionally, the low Dutch foreknowledge is rather surprising since the $\mathrm{Na}$ tional Institute for Public Health and Environment of the Dutch Ministry of Health, Welfare and Sports published a report on the replacement of meat and dairy by more sustainable protein sources several years ago [40]. Consequently, alternative protein-based convenience food products, like a spirulina burger and insect meatballs, are already commercially available in the Netherlands [41]. Of the French consumers who knew about microalgae in general, $80 \%$ knew of spirulina in particular, while only $74 \%$ of the German and $67 \%$ of the Dutch consumers who knew about microalgae in general were acquainted with spirulina in particular. In case spirulina was known, approximately $1 / 3$ of the consumers in France and Germany had already tried it (28\% and $30 \%$, resp.). Only $20 \%$ of the Dutch consumers who stated that they knew spirulina had already eaten it. According to these numbers, there is still a need to increase the prominence of microalgae in general, and of spirulina in particular, as relevant food ingredient. In order to identify possibilities to increase consumer awareness regarding consequences of meat consumption and the advantages of alternative protein sources, Hartmann and Siegrist [42] reviewed several studies and found 
TABLE 3: Novelty, interest, overall liking, and expected flavor liking as a function of experimental factors product and benefits controlled for position (presentation order) and country (M1).

\begin{tabular}{lccccccccc}
\hline & & \multicolumn{2}{c}{ Novelty } & \multicolumn{2}{c}{ Interest } & \multicolumn{2}{c}{ Overall liking } & \multicolumn{2}{c}{$\begin{array}{c}\text { Expected flavor } \\
\text { liking }\end{array}$} \\
Fixed effects & df, 3093 & $F$ & $p$ & $F$ & $p$ & $F$ & $p$ & $F$ & $p$ \\
\hline Position & 1 & 37.03 & 0.001 & 15.69 & 0.001 & 18.67 & 0.001 & 5.12 & 0.024 \\
Country & 2 & 49.19 & 0.001 & 7.14 & 0.001 & 2.66 & 0.070 & 0.24 & 0.786 \\
\hline Product & 2 & 34.98 & 0.001 & 134.30 & 0.001 & 135.50 & 0.001 & 130.93 & 0.001 \\
Benefit & 2 & 2.00 & 0.136 & 5.24 & 0.005 & 6.99 & 0.001 & 7.53 & 0.001 \\
Product $*$ benefit & 4 & 2.15 & 0.072 & 3.71 & 0.005 & 1.74 & 0.138 & 1.90 & 0.108 \\
\hline
\end{tabular}

that strategies to motivate environmentally friendly protein consumption behavior are lacking. They came to the conclusion that nudging strategies towards reduced meat consumption need to be established. Part of these nudging strategies could be convenient algae food products, served in a familiar context, as presented in this study.

\subsection{Consumer Acceptance}

3.2.1. Main Effects of Product-Benefit Combinations on Consumer Ratings. Model M1 introduced the experimental factors product, benefit, and their interaction and controlled for the position of the product-benefit combination in the order design and for a country main effect in scale usage. Significant differences in interest, overall liking, and expected flavor liking were due to both factors, that is, products and benefits, whereas the product $*$ benefit interaction was only significant regarding interest (Table 3 ).

Figure 3 visualizes the marginal means for M1. Across all DV, pasta came out on top. Regarding overall liking, consumers preferred pasta $\left(M=5.47^{\mathrm{a}}\right)$ clearly over sushi $\left(M=4.87^{\mathrm{b}}\right)$ and jerky $\left(M=4.34^{\mathrm{c}}\right)$ (means with different superscript letters differ significantly). Concerning overall liking of the benefits, healthy spirulina $\left(M=4.99^{\mathrm{a}}\right)$ is preferred over sustainable spirulina $\left(M=4.75^{\mathrm{b}}\right)$. This finding coincides with the results of Tobler et al. [43] who found that health or taste claims have a stronger impact on consumption behavior than environmental motives. Consequently, marketing strategies should not focus solely on sustainability morals in order to successfully induce consumption pattern changes. A main effect of the benefit was not found regarding novelty; that is, none of the benefits of spirulina were perceived as more novel than any other. However, a small product effect rendered novelty of sushi with spirulina as a bit less novel than pasta or jerky with spirulina, which confirms the flavor pairing strategy intended with the sushi concept.

Interest is the only DV where a product $*$ benefit interaction reached significance $(F(4,3093)=3.71 ; p=0.005)$. It was highest for healthy pasta and lowest for a sustainable jerky. Jerky is generally of lowest interest and least liked across all scales; however, if presented with the innovative benefit, it was viewed as more acceptable and interesting than with the other benefits. This is rather surprising, considering the fact that beef jerky itself is a product of an ancient preservation technique that is based on dehydration through drying [44]. Nevertheless, beef jerky is experiencing a revival and is nowadays marketed as a trendy savory protein snack with concentrated flavor and chewy texture that appears innovative and novel to younger generations.

3.2.2. Familiarity as a Mediator for Product Liking. Pasta turned out to be more familiar compared with sushi and jerky. It is a staple food with a long tradition in countries across Europe. It is flexible when it comes to combining it with other dishes and sauces, is easy to prepare, and therefore makes it a familiar food product.

Consequently, it turned out that product liking was partly mediated by familiarity with the product category. Familiarity with the product categories (ICC 30\%) varies strongly between the three products $(F(2,3102)=544.80$; $p=0.001$; full model not shown) and pasta turned out to be most familiar. It was on average consumed on a monthly basis $\left(M=-0.03^{\mathrm{a}}\right)$. Sushi was less often consumed $\left(M=-0.39^{\mathrm{b}}\right)$, and jerky $\left(M=-0.76^{\mathrm{c}}\right)$ was never tasted by a majority of the consumers. Table 4 reports model M2 for overall liking $(\mathrm{BIC}=13033$, smaller than for $\mathrm{M} 1=13298)$ which extends M1 by familiarity and its interactions with the experimental factors. Since familiarity strongly predicts consumer evaluations $(F(1,3084)=268.95 ; p<0.001)$, the product main effect on evaluations partly diminished ( $F(2$, 3084) $=2.90 ; p=0.055)$.

Figure 4 illustrates paths $\mathrm{a}$ and $\mathrm{b}$ of the mediation. Overall liking of the spirulina products was shown to depend on familiarity with the product category (path b). However, the familiarity slope was not as strong when pasta was concerned. As already mentioned, the product categories themselves possess different levels of average familiarity (path a, depicted by stars in Figure 4).

Thus, the spirulina products evoked an overall liking according to mere familiarity with the product category. In turn, it implies that, if the product categories were equal in familiarity (e.g., all consumed regularly), the spirulina products would have received more or less the same liking. It can be concluded that different product categories are conceivable with spirulina as long as the category is sufficiently familiar for the targeted consumers. Similar findings can be reported for soy products, where hedonic responses have been shown to be more positive when familiar than when perceived as unfamiliar by consumers [45]. Familiarity with the product category has an impact on general acceptability as well as the willingness to try a new variant of 


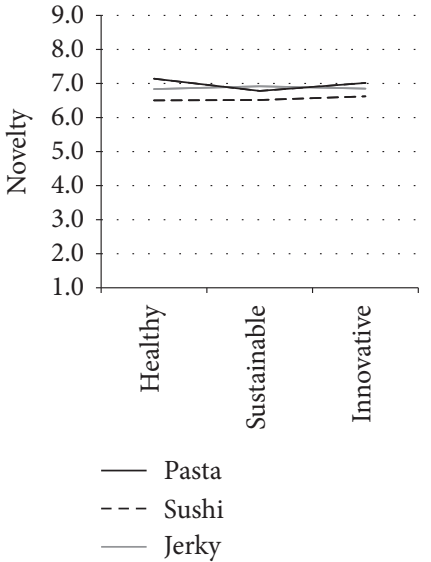

(a)

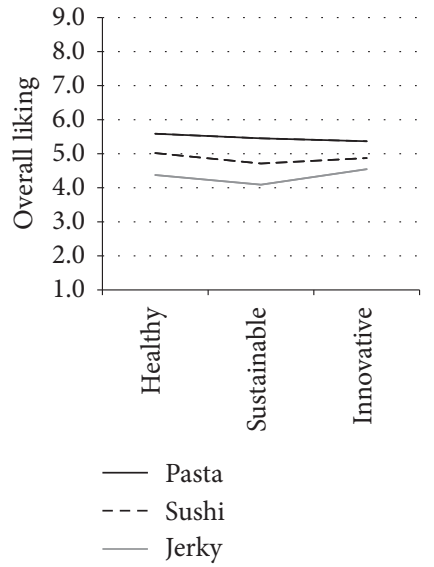

(c)

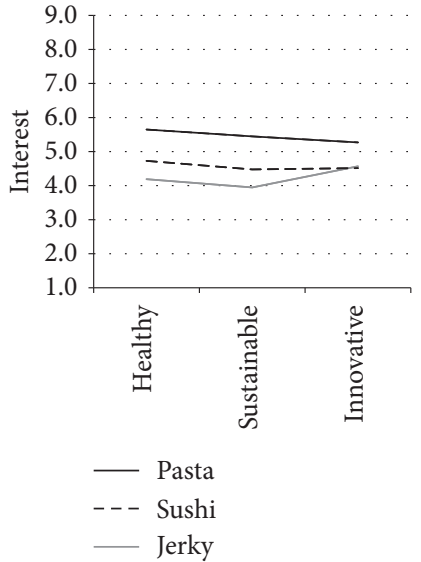

(b)

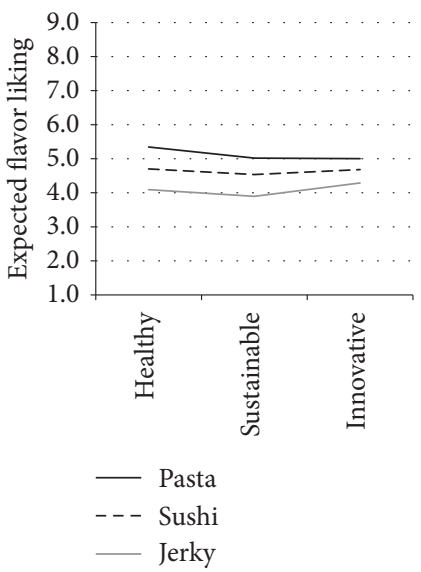

(d)

FIGURE 3: Novelty, interest, overall liking, and expected flavor liking measured on a 9-point scale as a function of product and benefit. Scales: (a) novelty ("not at all novel" (1) to "very novel" (9)), (b) interest ("not at all interesting" (1) to "very interesting" (9)), (c) overall liking ("dislike extremely" (1) to "like extremely" (9)) and (d) expected flavor liking ("very bad" (1) to "very good" (9)). Values depicted are marginal means derived from M1.

TABLE 4: Overall liking as a function of the experimental factors product and benefits controlled for country and position (presentation order), extended by familiarity and its interactions (M2).

\begin{tabular}{lccc}
\hline & & \multicolumn{2}{c}{ Overall liking } \\
Fixed effects & df, 3084 & $F$ & $p$ \\
\hline Position & 1 & 20.91 & 0.001 \\
Country & 2 & 1.35 & 0.258 \\
\hline Product & 2 & 2.90 & 0.055 \\
Benefit & 2 & 0.79 & 0.455 \\
Product $*$ benefit & 4 & 1.00 & 0.407 \\
\hline Familiarity & 1 & 268.95 & 0.001 \\
Familiarity $*$ product & 2 & 15.89 & 0.001 \\
Familiarity $*$ benefit & 2 & 1.87 & 0.155 \\
Familiarity $*$ product $*$ benefit & 4 & 0.56 & 0.689 \\
\hline
\end{tabular}

that category $[46,47]$, which will be of importance in sensory testing of spirulina-filled pasta and help to overcome potential food neophobia.

3.2.3. Examining Moderation by Country. Although M3 fitted better than M1 (e.g., for overall liking BIC M3 = 13293

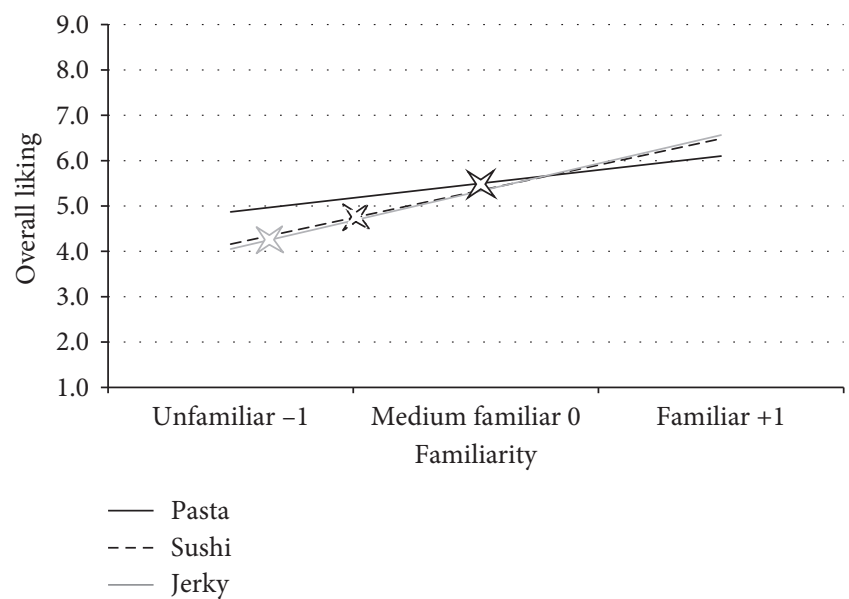

FIGURE 4: Overall liking of spirulina as a function of familiarity with product category (stars mark the average familiarity of each product category).

smaller than BIC M1=13298), country moderations of experimental factors were small (Table 5). Main effects were more or less pronounced, for example, German consumers 
TABLE 5: Experimental factors product, benefit, country, and their interaction as moderators for the dependent variables novelty, interest, overall liking, and expected flavor liking (M3).

\begin{tabular}{|c|c|c|c|c|c|c|c|c|c|}
\hline \multirow[b]{2}{*}{ Fixed effects } & \multirow[b]{2}{*}{ df, 3077} & \multicolumn{2}{|c|}{ Novelty } & \multicolumn{2}{|c|}{ Interest } & \multicolumn{2}{|c|}{ Overall liking } & \multicolumn{2}{|c|}{$\begin{array}{c}\text { Expected flavor } \\
\text { liking }\end{array}$} \\
\hline & & $F$ & $p$ & $F$ & $p$ & $F$ & $p$ & $F$ & $p$ \\
\hline Position & 1 & 36.48 & 0.001 & 14.76 & 0.001 & 18.11 & 0.001 & 4.39 & 0.036 \\
\hline Country & 2 & 49.24 & 0.001 & 7.29 & 0.001 & 2.57 & 0.077 & 0.22 & 0.800 \\
\hline Product & 2 & 37.22 & 0.001 & 135.93 & 0.001 & 136.55 & 0.001 & 131.10 & 0.001 \\
\hline Benefit & 2 & 1.98 & 0.138 & 4.84 & 0.008 & 6.66 & 0.001 & 7.14 & 0.001 \\
\hline Product $*$ benefit & 4 & 2.29 & 0.058 & 3.74 & 0.005 & 1.76 & 0.134 & 1.98 & 0.095 \\
\hline Country $*$ product & 4 & 10.97 & 0.001 & 2.46 & 0.043 & 2.14 & 0.073 & 1.92 & 0.104 \\
\hline Country $*$ benefit & 4 & 1.11 & 0.348 & 0.79 & 0.533 & 1.08 & 0.367 & 0.46 & 0.764 \\
\hline Country $*$ product $*$ benefit & 8 & 2.77 & 0.005 & 0.85 & 0.561 & 0.85 & 0.559 & 1.28 & 0.249 \\
\hline
\end{tabular}

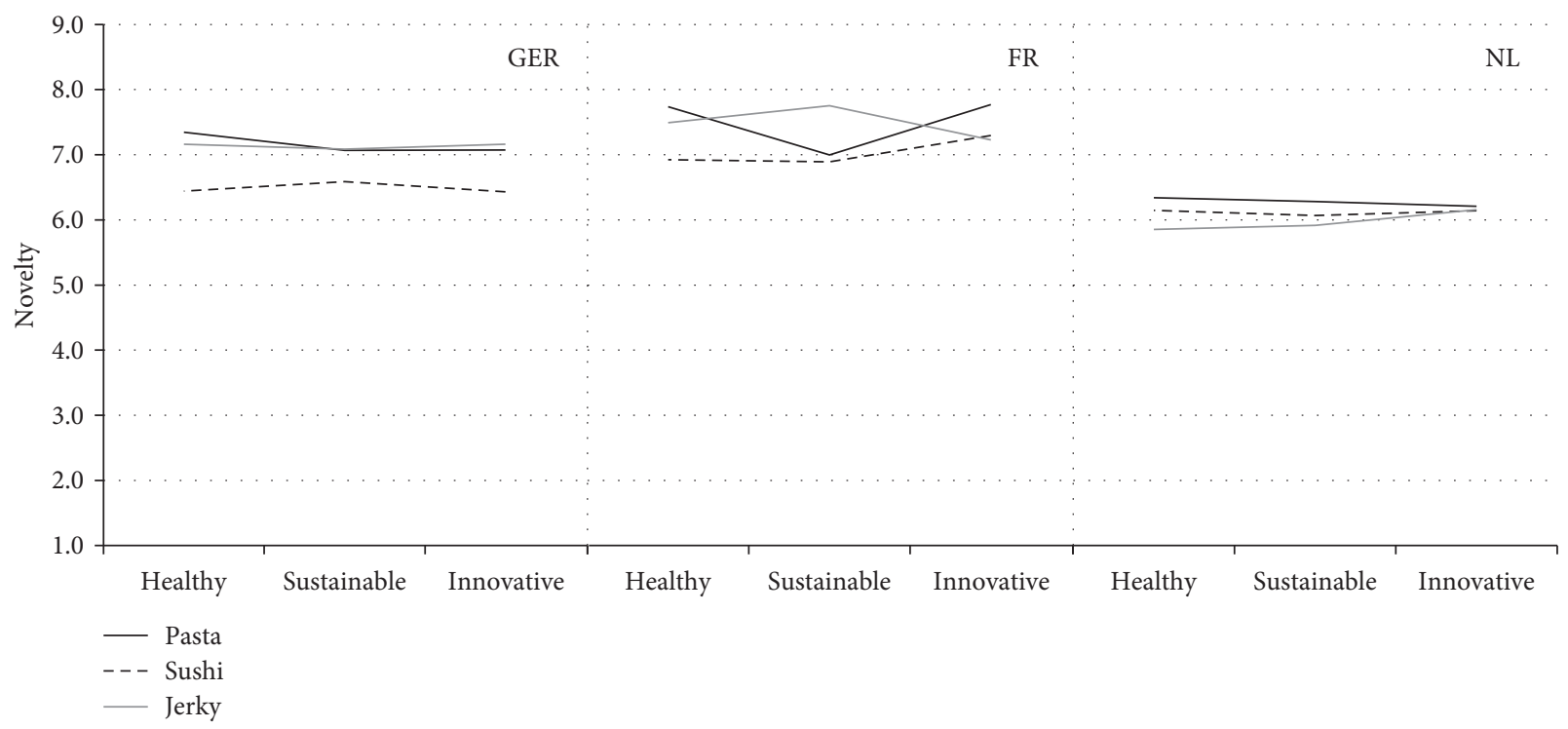

Figure 5: Novelty (9-point scale ("not at all novel" (1) to "very novel" (9))) as a function of product, benefit, and country (marginal means from M3).

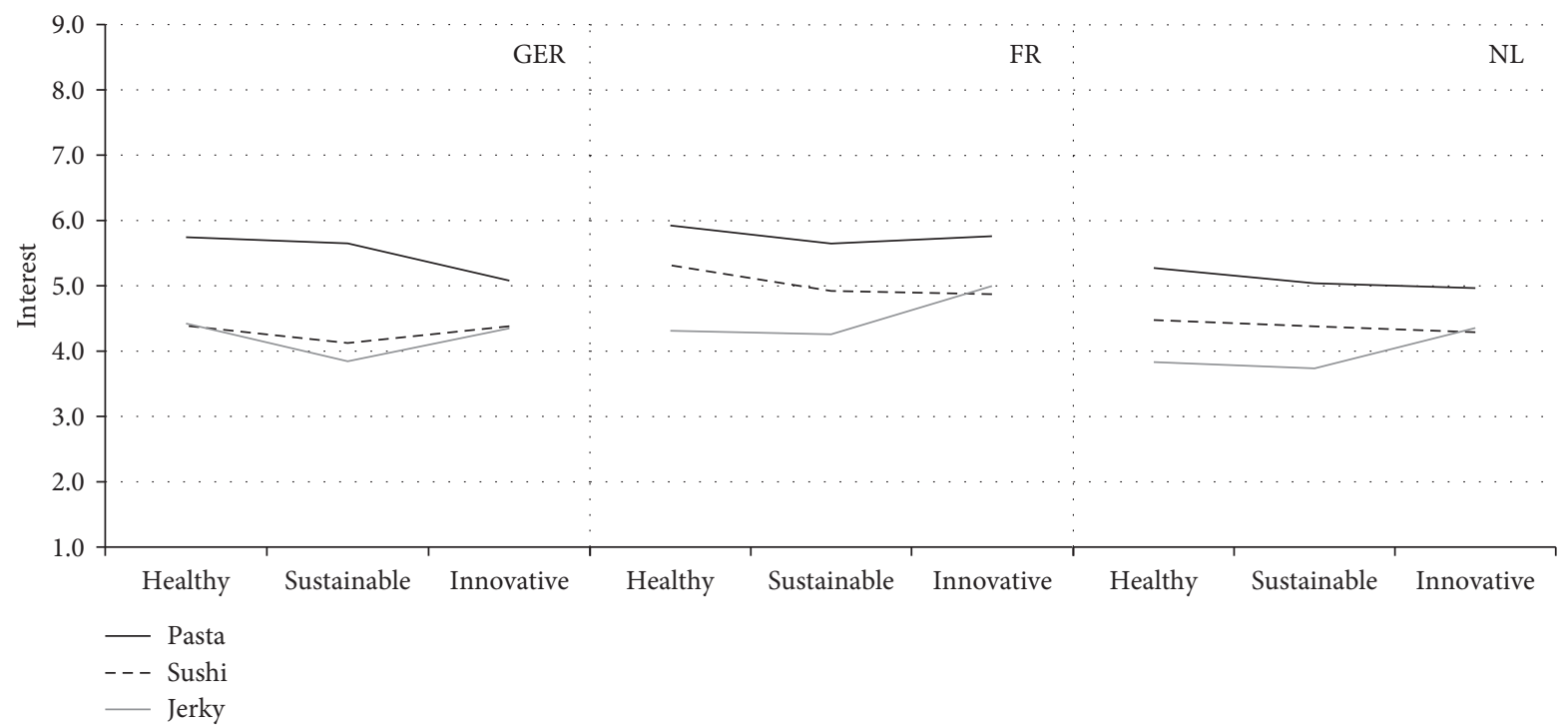

FiguRE 6: Interest (9-point scale ("not at all interesting" (1) to "very interesting" (9))) as a function of product, benefit, and country (marginal means from M3). 
clearly liked spirulina pasta (marginal means $5.70^{\mathrm{a}}, 4.94^{\mathrm{b}}$, and $4.60^{\mathrm{b}}$ for pasta, sushi, and jerky, resp.) while French consumers particularly dislike spirulina jerky (marginal means $5.47^{\mathrm{a}}, 4.95^{\mathrm{b}}$, and $4.18^{\mathrm{c}}$ for pasta, sushi, and jerky, resp.).

Country interactions reached significance only for novelty and interest evaluations. Regarding novelty (Figure 5), French consumers placed sustainable spirulina jerky over sustainable spirulina pasta; Germany and France were of different opinions concerning innovative spirulina sushi, and for the Dutch healthy spirulina jerky seems least novel. Regarding interest, German consumers do not differentiate much between their interest in sushi or jerky (marginal means $5.49^{\mathrm{a}}, 4.30^{\mathrm{b}}$, and $4.20^{\mathrm{b}}$ for pasta, sushi, and jerky), whereas French (marginal means $5.78^{\mathrm{a}}, 5.04^{\mathrm{b}}$, and $4.52^{\mathrm{c}}$ ) and Dutch (marginal means $5.09^{\mathrm{a}}, 4.38^{\mathrm{b}}$, and $3.98^{\mathrm{c}}$ ) consumers do so (Figure 6).

However, cross-country similarities were larger than differences. Thøgersen [48] recently clustered 10 European countries and identified three food-related lifestyle regions; Germany, France, and the Netherlands were grouped together with the UK. He found that the cluster in itself is not homogeneous, and segments are differently distributed. Nevertheless, the segment pattern is shared across countries within one region which might be an explanation why country differences in the present study are only found to be small.

It should be noted that the consumer evaluations in the current study are based on visual stimuli only; experiencing the taste of food might overrule the effect of visual components [49]. Also the acceptance of potential side dishes of the main meal item of interest might be of relevance for consumers to holistically evaluate a product in a survey [50]. The comparably low overall liking scores throughout the study can be explained by the fact that sensory experience is decisive when it comes to repeating a trial purchase. Consequently, more information is needed both from a consumer and research perspective, since a product with bad taste will not be bought again, even if healthy or sustainable [12].

\section{Conclusions}

The acceptance of three different products based on the microalga spirulina was investigated across three European countries. Familiarity with product categories, which was deduced from the frequency of consumption of the categories, proved to be a mediator. That is, different product categories are conceivable with spirulina as long as the category is sufficiently familiar for the targeted consumers. Overall, pasta was most liked across countries, with country differences being minor. This indicates that product marketing does not need to be culture-specific. Yet, there is still a need to increase the prominence of microalgae in general, and for spirulina in particular, as relevant food ingredient. Future research will focus on the development of appealing flavors for different pasta fillings so that consumers can give a fully informed opinion about the products, and product optimization can commence.

\section{Data Availability}

The data used to support the findings of this study are available from the corresponding author upon request.

\section{Conflicts of Interest}

None of the authors of this paper has a financial or personal relationship with other people or organizations that could inappropriately influence or bias the content of the paper.

\section{Acknowledgments}

The authors appreciate the help of Sylvia Lüdtke Daldrup and Tim Viergutz, Unipark for technical assistance handling as well as Jennifer Provost and Melvin van der Mark for critically revising the translated questionnaires. The publication was funded by the Lower Saxony Vorab by the Ministry of Education and Culture (MWK, Grant no. ZN 3041).

\section{References}

[1] United Nations (UN), "World Population to 2300," February 2018, https://calculators.io/world-population-to-2300/.

[2] M. J. Boland, A. N. Rae, J. M. Vereijken et al., "The future supply of animal-derived protein for human consumption," Trends in Food Science and Technology, vol. 29, no. 1, pp. 62-73, 2013.

[3] H. Aiking, "Future protein supply," Trends in Food Science and Technology, vol. 22, no. 2-3, pp. 112-120, 2011.

[4] E. W. Becker, "Micro-algae as a source of protein," Biotechnology Advances, vol. 25, no. 2, pp. 207-210, 2007.

[5] B. Ak, E. Avşaroğlu, O. Işık, G. Özyurt, E. Kafkas, and L. Uslu, "Nutritional and physicochemical characteristics of bread enriched with microalgae spirulina platensis," International Journal of Engineering Research and Application, vol. 6, no. 12, pp. 30-38, 2016.

[6] M. Carcea, M. Sorto, C. Batello et al., "Nutritional characterization of traditional and improved dihé, alimentary bluegreen algae from the lake Chad region in Africa," LWT-Food Science and Technology, vol. 62, no. 1, pp. 753-763, 2015.

[7] B. Vaz da Silva, J. B. Moreira, M. G. de Morais, and J. A. V. Costa, "Microalgae as a new source of bioactive compounds in food supplements," Current Opinion in Food Science, vol. 7, pp. 73-77, 2016.

[8] O. Ciferri, "Spirulina, the edible microorganism," Microbiological Reviews, vol. 47, no. 4, pp. 551-578, 1983.

[9] A. I. A. Costa and W. M. F. Jongen, "New insights into consumer-led food product development," Trends in Food Science and Technology, vol. 17, no. 8, pp. 457-465, 2006.

[10] H. Moskowitz and J. Hartmann, "Consumer research: creating a solid base for innovative strategies," Trends in Food Science and Technology Technology, vol. 19, no. 11, pp. 581589, 2008.

[11] S. Grahl, M. Palanisamy, M. Strack, L. Meier-Dinkel, S. Toepfl, and D. Mörlein, "Towards more sustainable meat alternatives: how technical parameters affect the sensory properties of extrusion products derived from soy and algae," Journal of Cleaner Production, vol. 198, pp. 962-971, 2018.

[12] K. G. Grunert and H. C. M. van Trijp, "Consumer-oriented new product development," in Encyclopedia of Agriculture 
and Food Systems, N. K. van Alfen, Ed., Vol. 2, pp. 375-386, Elsevier, New York, NY, USA, 2014.

[13] R. Barrena and M. Sánchez, "Neophobia, personal consumer values and novel food acceptance," Food Quality and Preference, vol. 27, no. 1, pp. 72-84, 2012.

[14] L. Guerrero, M. D. Guàrdia, J. Xicola et al., "Consumer-driven definition of traditional food products and innovation in traditional foods. A qualitative cross-cultural study," Appetite, vol. 52, no. 2, pp. 345-354, 2009.

[15] Ö. Tokusoglu and M. K. Ünal, "Biomass nutrient profiles of three microalgae: spirulina platensis, chlorella vulgaris and isochrysis galbana," Journal of Food Science, vol. 68, no. 4, pp. 1144-1148, 2003.

[16] T. Hirata, M. Tanaka, M. Ooike, T. Tsunomura, and M. Sakaguchi, "Antioxidant activities of phycocyanobilin prepared from Spirulina platensis," Journal of Applied Phycology, vol. 12, no. 3-5, pp. 435-439, 2000.

[17] J. Falquet, "The nutritional aspects of spirulina," 2017, http:// www.antenna.ch/wp-content/uploads/2017/03/AspectNut_ UK.pdf.

[18] Y.-Y. Fan and R. S. Chapkin, "Importance of dietary g-linolenic acid in human health and nutrition," Journal of Nutrition, vol. 128, no. 9, pp. 1411-1414, 1998.

[19] S. Sergeant, E. Rahbar, and F. H. Chilton, "Gamma-linolenic acid, dihomo-gamma linolenic, eicosanoids and inflammatory processes," European Journal of Pharmacology, vol. 785, pp. 77-86, 2016.

[20] G. Gutiérrez-Salmeán, L. Fabila-Castillo, and G. ChamorroCevallos, "Nutritional and toxicological aspects of spirulina (Arthrospira)," Nutricion Hospitalaria, vol. 32, no. 1, pp. 34-40, 2015.

[21] T. Meier, O. Christen, E. Semler et al., "Balancing virtual land imports by a shift in the diet. Using a land balance approach to assess the sustainability of food consumption. Germany as an example," Appetite, vol. 74, pp. 20-34, 2014.

[22] V. Prudêncio da Silva, H. M. G. van der Werf, A. Spies, and S. R. Soares, "Variability in environmental impacts of Brazilian soybean according to crop production and transport scenarios," Journal of Environmental Management, vol. 91, no. 9, pp. 1831-1839, 2010.

[23] S. Smetana, M. Sandmann, S. Rohn, D. Pleissner, and V. Heinz, "Autotrophic and heterotrophic microalgae and cyanobacteria cultivation for food and feed: life cycle assessment," Bioresource Technology, vol. 245, pp. 162-170, 2017.

[24] S. E. Taelman, S. De Meester, W. Van Dijk, V. da Silva, and J. Dewulf, "Environmental sustainability analysis of a proteinrich livestock feed ingredient in the Netherlands: microalgae production versus soybean import," Resources, Conservation and Recycling, vol. 101, pp. 61-72, 2015.

[25] M. S. Selmo and M. M. Salas-Mellado, "Technological quality of bread from rice flour with spirulina," International Food Research Journal, vol. 21, no. 4, pp. 1523-1528, 2014.

[26] S. M. R. Joshi, M. B. Bera, and P. S. Panesar, "Extrusion cooking of maize/spirulina mixture: factors affecting expanded product characteristics and sensory quality," Journal of Food Processing and Preservation, vol. 38, no. 2, pp. 655664, 2014.

[27] P. Singh, R. Singh, A. Jha, P. Rasane, and A. K. Gautam, "Optimization of a process for high fibre and high protein biscuit," Journal of Food Science and Technology, vol. 52, no. 3, pp. 1394-1403, 2015.

[28] M. Tańska, I. Konopka, and M. Ruszkowska, "Sensory, physico-chemical and water sorption properties of corn extrudates enriched with spirulina," Plant Foods for Human Nutrition, vol. 72, no. 3, pp. 250-257, 2017.

[29] G. Özyurt, L. Uslu, I. Yuvka et al., "Evaluation of the cooking quality characteristics of pasta enriched with spirulina platensis," Journal of Food Quality, vol. 38, no. 4, pp. 268-272, 2015.

[30] N. Zouari, M. Abid, N. Fakhfakh et al., "Blue-green algae (Arthrospira platensis) as an ingredient in pasta: free radical scavenging activity, sensory and cooking characteristics evaluation," International Journal of Food Sciences and $\mathrm{Nu}$ trition, vol. 62, no. 8, pp. 811-813, 2011.

[31] H. Beheshtipour, A. M. Mortazavian, R. Mohammadi, S. Sohrabvandi, and K. Khosravi-Darani, "Supplementation of spirulina platensis and chlorella vulgaris algae into probiotic fermented milks," Comprehensive Reviews in Food Science and Food Safety, vol. 12, no. 2, pp. 144-154, 2013.

[32] S. Askegaard and T. K. Madsen, "European food cultures: an exploratory analysis of food related preferences and behaviour in European regions," March 2018, http://citeseerx.ist. psu.edu/viewdoc/download?doi=10.1.1.463.4394\&rep=rep1\& type $=$ pdf.

[33] M. B. Ruby, S. J. Heine, S. Kamble, T. K. Cheng, and M. Waddar, "Compassion and contamination. Cultural differences in vegetarianism," Appetite, vol. 71, pp. 340-348, 2013.

[34] J. de Boer, M. Helms, and H. Aiking, "Protein consumption and sustainability: diet diversity in EU-15," Ecological Economics, vol. 59, no. 3, pp. 267-274, 2006.

[35] R. Januszewska, Z. Pieniak, and W. Verbeke, "Food choice questionnaire revisited in four countries. Does it still measure the same?," Appetite, vol. 57, no. 1, pp. 94-98, 2011.

[36] G. L. Lilien, P. D. Morrison, K. Searls, M. Sonnack, and E. Hippel von, "Performance assessment of the lead user ideageneration process for new product development," Management Science, vol. 48, no. 8, pp. 1042-1059, 2002.

[37] E. van Kleef, H. C. M. van Trijp, and P. Luning, "Consumer research in the early stages of new product development: a critical review of methods and techniques," Food Quality and Preference, vol. 16, no. 3, pp. 181-201, 2005.

[38] H. McGee, "Chapter 10: cereal doughs and batters: bread, cakes, pastry, pasta," in McGee on Food and Cooking, pp. 515-579, Hodder and Stoughton Ltd., London, UK, 2004.

[39] R. M. Baron and D. A. Kenny, "The moderator-mediator variable distinction in social psychological research: conceptual, strategic, and statistical considerations," Journal of Personality and Social Psychology, vol. 51, no. 6, pp. 11731182, 1986.

[40] M. J. Tijhuis, J. Ezendam, S. Westenbrink, C. van Rossum, and L. Temme, "Replacement of meat and dairy by more sustainable protein sources in the Netherlands," April 2018, https://rivm.openrepository.com/rivm/bitstream/10029/260292/ 3/350123001.pdf.

[41] J. House, "Consumer acceptance of insect-based foods in the Netherlands: academic and commercial implications," Appetite, vol. 107, pp. 47-58, 2016.

[42] C. Hartmann and M. Siegrist, "Consumer perception and behaviour regarding sustainable protein consumption: a systematic review," Trends in Food Science and Technology, vol. 61, pp. 11-25, 2017.

[43] C. Tobler, V. H. M. Visschers, and M. Siegrist, "Eating green. Consumers' willingness to adopt ecological food consumption behaviors," Appetite, vol. 57, no. 3, pp. 674-682, 2011.

[44] H. McGee, "Chapter 3: meat," in McGee on Food and Cooking, pp. 118-178, Hodder and Stoughton Ltd., London, UK, 2004. 
[45] A. Fenko, B. W. Backhaus, and J. J. van Hoof, "The influence of product- and person-related factors on consumer hedonic responses to soy products," Food Quality and Preference, vol. 41, pp. 30-40, 2015.

[46] Y. Martins and P. Pliner, "Human food choices: an examination of the factors underlying acceptance/rejection of novel and familiar animal and nonanimal foods," Appetite, vol. 45, no. 3, pp. 214-224, 2005.

[47] B. Wansink, "Changing eating habits on the home front: lost lessons from world war II research," Journal of Public Policy and Marketing, vol. 21, no. 1, pp. 90-99, 2002.

[48] J. Thøgersen, "Sustainable food consumption in the nexus between national context and private lifestyle: a multi-level study," Food Quality and Preference, vol. 55, pp. 16-25, 2017.

[49] D. A. Zellner, M. Lankford, L. Ambrose, and P. Locher, "Art on the plate: effect of balance and color on attractiveness of, willingness to try and liking for food," Food Quality and Preference, vol. 21, no. 5, pp. 575-578, 2010.

[50] M. Jimenez, D. Rodriguez, N. Greene, D. A. Zellner, A. V. Cardello, and M. Nestrud, "Seeing a meal is not eating it: hedonic context effects differ for visually presented and actually eaten foods," Food Quality and Preference, vol. 41, pp. 96-102, 2015. 


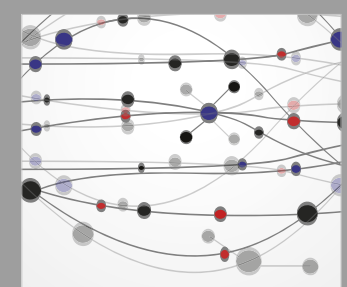

The Scientific World Journal
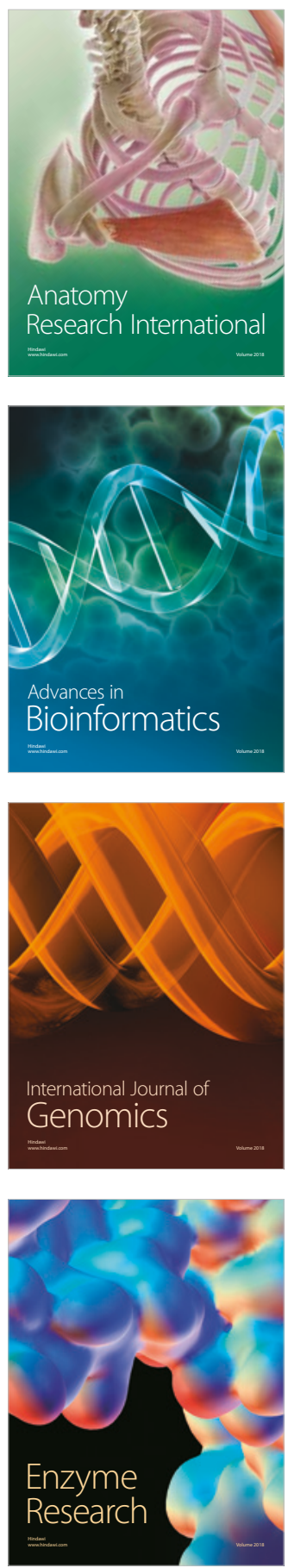
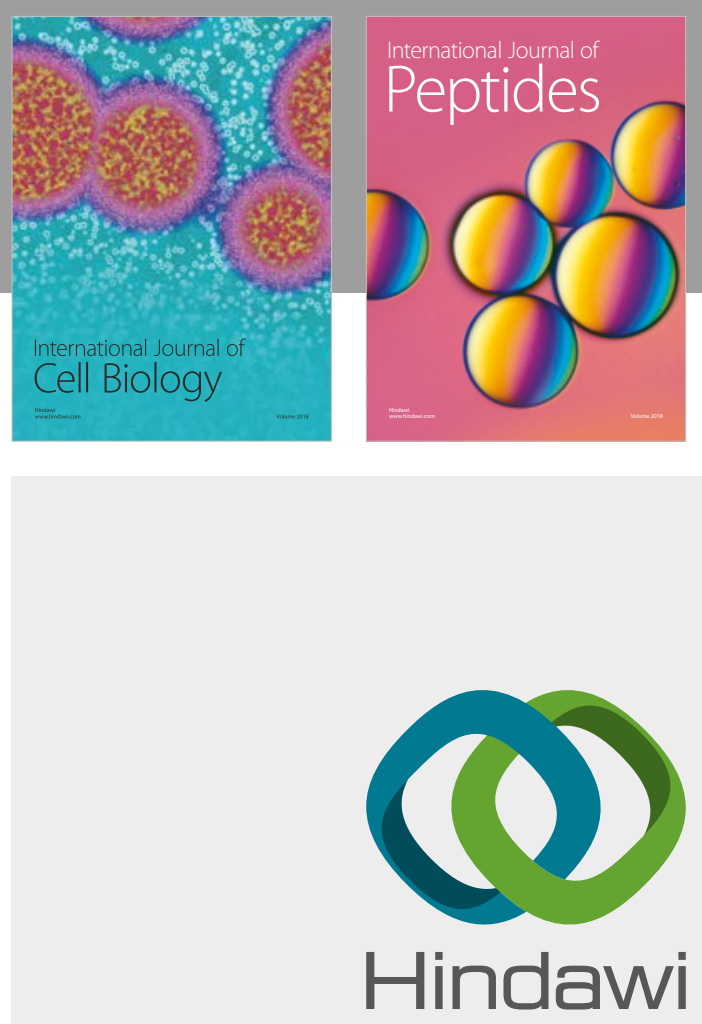

Submit your manuscripts at

www.hindawi.com
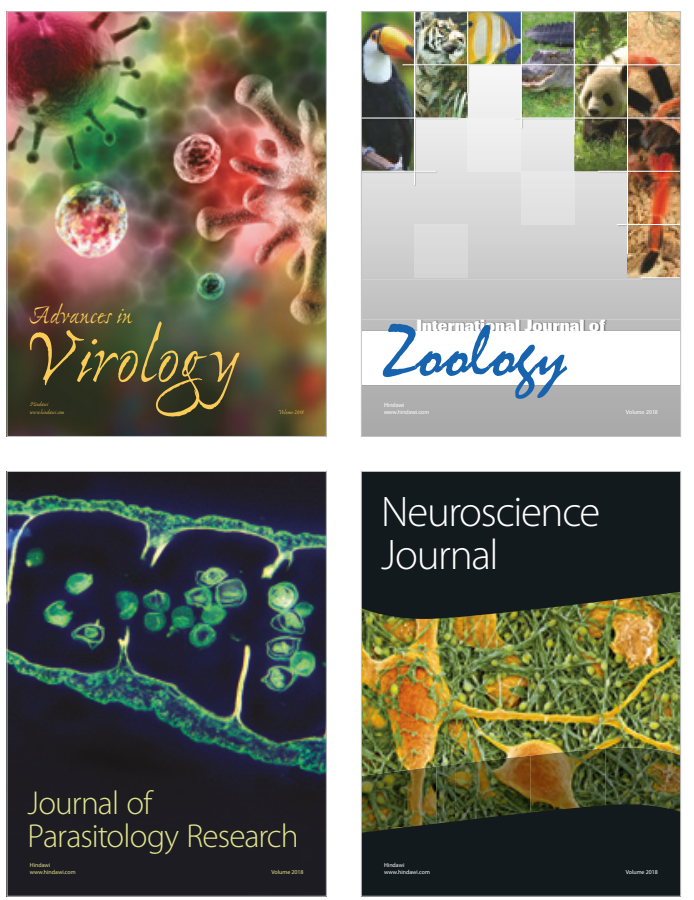
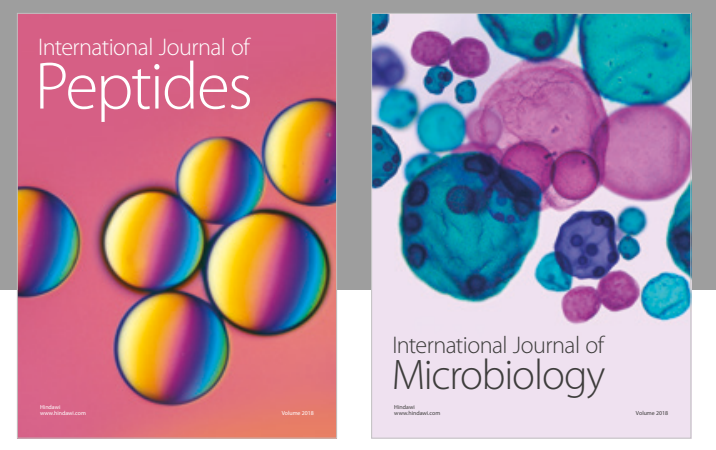

nternational Journal of Microbiology
Journal of
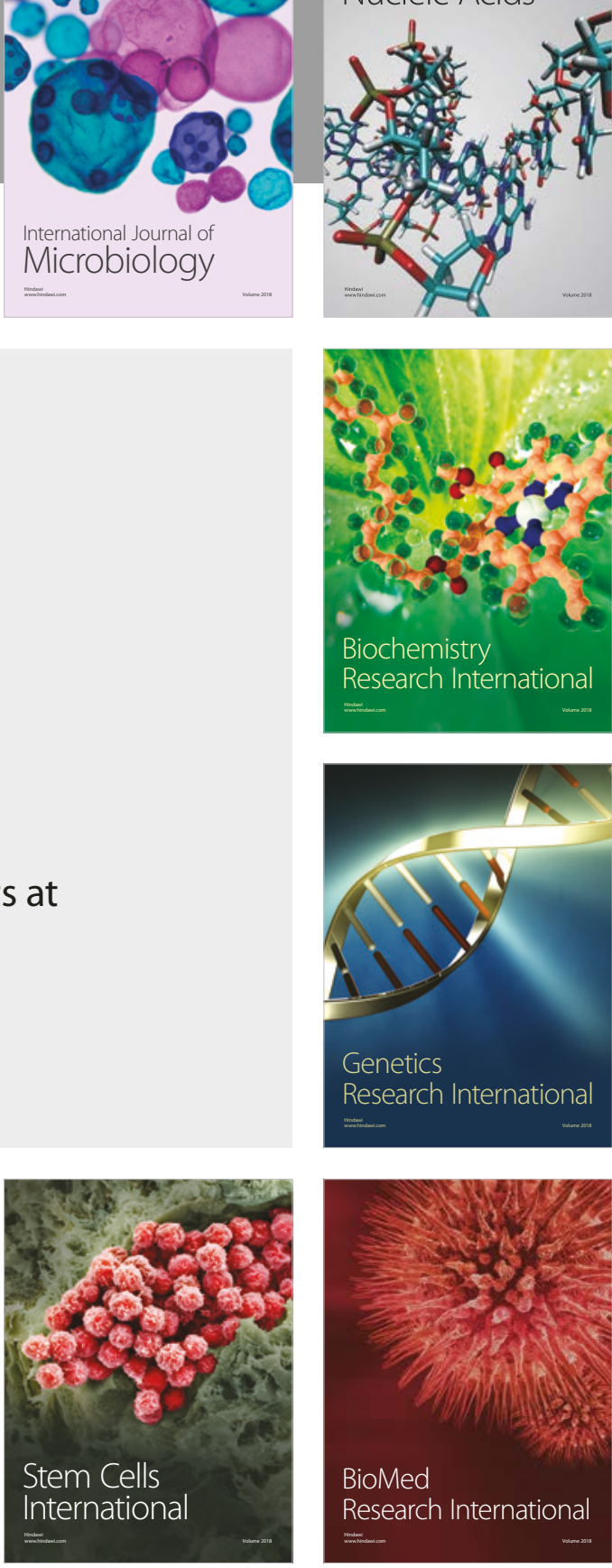
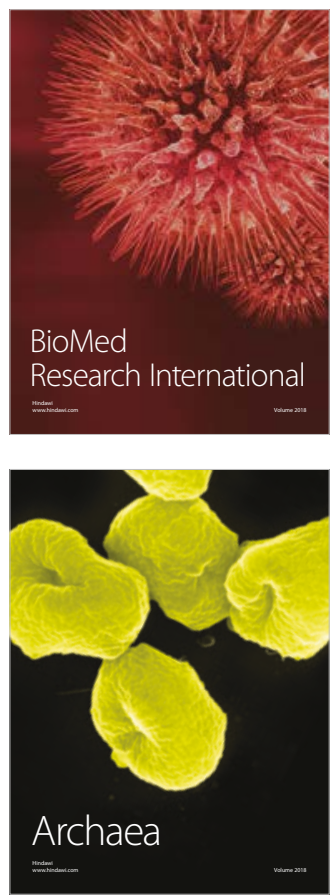